\title{
Phenolic compounds of Napek leave (Zizyphus spina-christi L.) as natural antioxidants
}

\author{
Maliha. A. AL-Marzooq \\ Food Science \& Nutrition Department, Faculty of Agriculture Science \& Foods, King Faisal University, Saudi Arabia
}

\section{Email address:}

malihasa@yahoo.com

\section{To cite this article:}

Maliha. A. AL-Marzooq. Phenolic Compounds of Napek Leave (Zizyphus Spina-Christi L.) as Natural Antioxidants. Journal of Food and Nutrition Sciences. Vol. 2, No. 5, 2014, pp. 207-214. doi: 10.11648/j.jfns.20140205.11

\begin{abstract}
Crude juices of Sidr (Zizyphus Spina-Christi L.) from leaves were obtained by hydraulic press. The levels of polyphenolic compounds in the (leaves) juice were 510.00 and $722.00 \mathrm{ppm}$. Aliquots of the concentrated sidr juice (leaves), represent 200, 400, 800 and 1600ppm and butylated hydroxyl toluene (BHT, 200ppm) were investigated by Rancimat method at $100^{\circ} \mathrm{C}$ and 1, 1-diphenyl-2-picrylhydrazyl (DPPH) free radical scavenging method. These compounds were administrated to rats daily for 6 weeks by stomach tube. The liver (Aspartate aminotransferase, alanine aminotransferase and alkaline phosphatase activities) and kidney (bilirubin, uric acid and creatinine) function tests and serum contents (total lipids, total cholesterol and low and high-density lipoproteins) were measured to assess the safety limits of the phenolic compounds in the sidr juice (fruits and leaves). The data of the aforementioned measurements indicates that the administration of sidr juice (leaves) did not cause any changes in liver and kidney functions. On the contrary, BHT at $200 \mathrm{ppm}$ induced significant increases in the enzyme activities and the serum levels of total lipids, uric acid and creatinine.
\end{abstract}

Keywords: Zizyphus Spina- Christi L., Phenolic Compounds, Antioxidants, Phytochemistry.

\section{Introduction}

Reactive oxygen species (Ros) readily attack and induce oxidative damage to various biomolecules including proteins, lipids, lipoproteins, and DNA. The oxidative damage is a crucial etiological factor implicated in several chronic human diseases, namely cardiovascular diseases, rheumatism, diabetes mellitus and cancer [1]. Based on growing interest in free radical biology and the lack of effective therapies for most chronic diseases, the usefulness of antioxidants in protection against these diseases is warranted. Antioxidants are chemical substances that reduce or prevent oxidation. They have the ability to counteract the damaging effects of free radicals in tissues and thus are believed to protect against cancer, arteriosclerosis, heart disease and several other diseases [2]. Many studies have shown that phenolic compounds display antioxidant activity as a result of their capacity to scavenge free radicals [3]. Phenolic compounds can also act as antioxidants by chelating metal ions, preventing radical formation and improving the antioxidant endogenous system [4]. These compounds are known to act as antioxidant not only because of their ability to donate hydrogen or electrons but also because they are stable radical intermediates.

Probably the most important natural phenolic are flavonoids because of their broad spectrum of chemical and biological activities, including antioxidant and free radical scavenging properties [5]. In fact, flavonoids have been reported as antioxidants, scavengers of a wide range of reactive oxygen species and inhibitors of lipid peroxidation [6]. These compounds which are widely distributed across the plant kingdom represent the most abundant antioxidants in the diet and they have gained tremendous interest as potential therapeutic agents against a wide variety of diseases, most of which involve oxidant damage [7]. The unusually wide pharmacological spectrum of flavonoids was originally thought to result from their antioxidant activity; however, recent studies suggest that various flavonoids may use other protective mechanisms are well.

Flavonoids have also been shown to be highly effective scavenging of most types of oxidizing molecules, including singlet oxygen and other various free radicals that are probably involved in several diseases. On the other hand, numerous studies have shown structure-activity relationships governing antioxidant capacities of flavonoids [8 and 9]. Food chemists have proposed the replacement of synthetic 
antioxidants such as butylhydroxyanisole (BHA) and butylhydroxytoluene (BHT), with natural ones because the synthetic antioxidants are suspected to be carcinogenic [10]. In summary, natural antioxidants are useful in the food industry as preservatives to increase the life of food products preventing the loss of their sensory and nutritional value.

Zizyphus spina-christi (L) locally known as sidr, is a multipurpose tree species belonging to the botanical family Rhamnaceae, and native to the warm temperatures and subtropical regions, including North Africa, South Europe, Mediterranean, Australia, Tropical America, South and East of Asia and Middle East [11]. Z. spina-christi is a shrub, sometimes a tall tree, reaching a height of $20 \mathrm{~m}$ and a diameter of $60 \mathrm{~cm}$; its bark is light grey, very cracked, scaly; trunk twisted; much branched, crown thick; shoots whitish, flexible, drooping; thorns in pairs, one straight. Its leaves are glabrous on upper surface, finely pubescent below, ovate-lanceolate or ellipsoid, apex acute or obtuse margins almost entire, lateral veins conspicuous. Flowers in cymes, subsessile, peduncle 1 to $3 \mathrm{~mm}$. fruit about $1 \mathrm{~cm}$ in diameter [12]. Z. spina chirsti has very nutritious fruits that are usually eaten fresh. The flowers are important source for honey bee. The winter honey (i.e Napek honey) collected from the flowers of the sidr is in high demand by citizens for its medicinal qualities in addition to its excellent taste and fragrant smell [13]. The fruits are applied on cuts and ulcers. They are also used to treat pulmonary ailments and fevers and to promote the healing of fresh wounds, for dysentery [14]. For along time, in folklore medicine, sidr has been used for the treatment of some diseases, such as digestive disorders, weakness, liver complaints, obesity, urinary troubles, diabetes, skin infections, loss of appetite, fever, phyaryngitis, bronchitis, anemia, diarrhea, and insomnia [15 and 16]. The leaves are applied locally to sores, and the roots are used to cure and prevent skin diseases [17]. The seeds are sedative and are taken sometime with buttermilk to halt nausea, vomiting and abdominal pains associated with pregnancy [18]. The leaves are applied as poultices and are helpful in liver troubles, as- thma and fever [19]. Z. spins-christi extract has also been reported it possesses protective effect against aflatoxicosis [20] and anti-conceptive properties in the rat and has a calming effect on the central nervous system. Flavonoids, alkaloids, triterpenoids, saponins, lipids, proteins, free sugar and mucilage are the main important compounds characterized in this plant [21]. A survey of the literature revealed that a number of cyclopeptide and isoquinoline alkaloids, flavonoids, terpenoids and their glycosides have been found to occur in various amount in most Ziziphus species. The leaves of these plants contain betulinic and ceanothic acids, various flavonoids, saponins, erols tannins and triterpenes [22]. The aqeous extract of $Z$. spina Christi stem bark has shown significant antibacterial activity [23, 24 and 25], antifungal [26], antinociceptive effects [17], antioxidant activity [11and 27]. Since Zizyphus Spina-Christi L. is a wild tree commonly available in Saudi Arabia and its fruits are used in folk medicine for treatment, it is therefore, the present study was undertaken to investigate the use of leaves and fruits extract of sidr as antioxidant and the study effect of crude sidr juice (leaves and fruits) on rat serum constituents.

\section{Materials \& Methods}

\subsection{Source of Sidr Leaves}

The leaves of sidr (Zizyphus spina-christi (L) were collected from trees growing in Al-Hasa (Saudi Arabia) during the year 2012. leaves are pruned annually in late May.

\subsection{Source of Sunflower Oil}

Refined sunflower oil was obtained from Savola Oil (Dammam, Saudi Arabia). The oil acid and peroxide values were $0.30 \mathrm{mg} \mathrm{KoH} \mathrm{g}^{-1}$ and 0.60 meq./ $\mathrm{kg}^{-1}$, respectively.

\subsection{Solvents, Reagents and Kits}

All solvents used throughout the whole work were analytical grade and distilled before use. Caffeic acid (98\%) and folin-Ciocalteau reagent were purchased from SigmaAldrich (St. Louis, MO, USA) and Gerbsaure Chemical Co. Ltd., Germany, respectively. Alkaline phosphatase (AP), aspartate aminotransferase (AST), alanine aminotransferase (ALT), bilirubin, creatinine, and uric acid kits obtained from Borhringer Ingelheim $\mathrm{GmbH}$, Ingelheim, Germany.

\subsection{Experimental Animals}

Albino male rats, 50 days old with an average weight of $60-70 \mathrm{~g}$ were obtained from the Faculty of Veterinary Medicine, King Faisal University, Al-Hasa, Saudi Arabia.

\subsection{Preparation of Crude Sidr Leaves Juice}

Sidr leaves were cleaned and remove seeds them pressed by hydraulic laboratory press. The resultant crude juice was concentrated using freeze dryer (Labconco Corporation, Kansas, City, Mo, USA) and kept in a brown bottle at $5^{\circ} \mathrm{C}$ until use.

\subsection{Determination of Total Polyphenolic}

The levels of total polyphenols of fresh crude sidr juice (leaves) were determined according to the method of Gutfinger [28]. Caffeic acid was served as a standard compound for the preparation of the calibration curve.

\subsection{Phenolic Fraction}

Phenolic fraction was isolated by solid phase extraction and analyzed by reversed-phase HPLC using a diode array UV detector [29]. A Hewlett-Packard series 1,100 liquid chromatographic system (Waldbronn, Germany) equipped with diode array detector and a lichrosorb Rp18 column (4.00mmid C250 mm, particle size 5mm, Merck, Darmstdt) used. Elution was performed at a flow rate of $1.00 \mathrm{ml} / \mathrm{min}$ 
with mobile phase of water/acetic acid (98:2 v/v, solvent A) and methanol/acetonitril (50:50, v/v, solvent B), starting with $5 \%$ B then increase to levels of $30 \%$ at $25 \mathrm{~min}, 40 \%$ at $35 \mathrm{~min}$., $52 \%$ at $40 \mathrm{~min}$; $70 \%$ at $50 \mathrm{~min}$., $100 \%$ at 55 min., and kept at this stage for $5 \mathrm{~min}$. Quantification of phenolic compounds was carried out at wave length of $280 \mathrm{~nm}$ using $P$-hydroxybenzoic acid as an internal standard.

\subsection{Oxidation System}

Different concentrations of phenolic compounds from sidr (leaves) (200, 400, 800 and 1600ppm) and BHT (200ppm) were individually add to sunflower oil to study their antioxidant behavior. The designation of an induction period, measured by using a Rancimat Instrument, was taken as a tool to compare the effectiveness of the phenolic compounds on sunflower oil stability.

\subsection{Designation of Induction Period by Rancimat}

Rancimat method was used to evaluate oxidative stability, because it is fast and reliable [30]. Stability was expressed as the oxidation induction time (hr) measured with the Rancimat 679 apparatus (Metrohm Co. Switzerland) using an oil sample of $5.0 \mathrm{~g}$ warmed to $100 \pm 2^{\circ} \mathrm{C}$, and an air flow of $20 \mathrm{l} / \mathrm{hr}$. the time taken to reach a fixed level of conductivity was measured.

\subsection{DPPH Free Radical-Scavenging Activity}

The DPPH free radical scavenging assay was carried out, as previously reported by [31] with some modification. The crude juice from sidr (leaves) at various concentrations (200, 400, 800 and 1600ppm) were added to a $0.06 \mathrm{~nm}$ DPPH solution in ethanol and reaction mixture was shaken vigorously. After incubation for $30 \mathrm{~min}$ at room temperature, the absorbance at $517 \mathrm{~nm}$ was recorded spectorphotometrically. Vitamin E was used as a reference as the test compound. A control solution, without the tested compound, was prepared in the same manner as the assay mixture. All the analysis was done in triplicate. The degree of discolorisation indicates the free radical scavenging efficiency of the substances. The antioxidant activity was calculated as an inhibitory effect (IE\%) of the DPPH radical formation as follows:

IE $\%=100 \mathrm{X} \quad\left(\mathrm{A}_{517 \mathrm{cntrol}}-\mathrm{A}_{517 \text { sample }} / \mathrm{A}_{517 \mathrm{cntrol}}\right)$, and expressed ad IC50. The IC50 value was defined as the concentration (in $\mu \mathrm{g} / \mathrm{ml}$ ) of the compound required to scavenge the DPPH radical by $50 \%$.

\subsection{Nutrition Experiments}

A total of eighty albino male rats were raised in the animal house of faculty of Agriculture Science \& Foods, King Faisal University Al-Hasa, Saudi Arabia. The animals were fed on a basal diet for 7 days as an adaptation period. The basal diet was formulated according to [32] method and consisted of casein $(15 \%)$, corn oil $(10 \%)$, cellulose $(5 \%)$, salt mixture $(4 \%)$, vitamin mixture $(1 \%)$ and starch $(65 \%)$. Water was available ad libitum. Known volumes of the concentrated crude sidr (leaves) juice were dissolved in a mixture of distilled water and Tween $20(12: 1, \mathrm{~V} / \mathrm{V})$ to obtain polyphenols concentrations of 200, 400, 800 and $1600 \mathrm{ppm}$. BHT solution (200ppm) was prepared exactly as mentioned above for sidr juice (leaves). The rats divided into ten groups and each group comprised eight rats. The first group presents the control rats, second group was given BHT at 200ppm, third, fourth, fifths and sixth were given 200, 400, 800 and 1600 of polyphenols from sidr leaves juice. Each rat group was stomach ingested by gavages daily $(1 \mathrm{ml})$ from the crude sidr juice (leaves) and BHT solution for 6 weeks.

\subsection{Blood Samples}

Blood samples were taken at the start of the experiment and after 1, 2, 3, 4, 5, and 6 weeks of the administration of the crude sidr juice (leaves) and BHT. The blood samples were obtained from orbital plexus venous by means of fine capillary glass tubes according to the method outlined by [33]. It was not possible to collect $10 \mathrm{ml}$ blood from a single rat; hence the blood of eight rats in each group was pooled. The blood samples were placed in dry and clean centrifuge tubes and allowed to clot for $1-2 \mathrm{~h}$ at room temperature. Sera were then removed using a Pasteur pipette and centrifuged for $20 \mathrm{~min}$ at $110 \mathrm{rpm}$. The clean supernatant Sera were then kept frozen until analysis.

\subsection{Sera Analysis}

Alanine aminotransferase ALT (E. C. 2. 6. 1. 2), Aspartate aminotransferase AST (E. C. 2. 6. 1. 1) and AP (E C. 3. 1. 3. 1), activities were measured according to the methods described by [34, 35 and 36], respectively. Types of bilirubin (total and direct), urea and acid were determined according to the methods described by [37, 38 and 39], respectively. The levels of serum cholesterol, low and high density lipoproteins and total lipids were determined according to the methods outlined by [40, 41 and 42]. Each determination was carried out in triplicate and the mean values are presented in the text.

\subsection{Statistical Analysis}

Data were collected and expressed and expressed as the mean \pm saturated deviation of three independent experiments and analysis for statistical significant from control, using the Dunnett test (SPSS 11.5 Statistics Software; SPSS, Chicago, IL).

\section{Results \& Discussion}

\subsection{Polyphenols Content}

There is currently great interest world-wide in finding new and safe antioxidant from natural sources to prevent oxidative rancidity of foods and so the present study focused on extracts of sidr containing polyphenols, which do not have an undesirable odor when inhaled through the 
nose or an undesirable and tongue taste. Although, in this publication, the active principal is assumed to be polyphenolic in origin the occurrence of other unidentified active principles is not excluded. Thus though reference is always made to the polyphenolic material as being antioxidant, the case is that we have proved it unequivocally. The total polyphenols contents obtained are shown in Table 1. The concentration of polyphenols in the leaves sidr was $722.00 \mathrm{ppm}$.

Table 1. Phenolic contents as Caffeic acid of sidr (Zizyphus spina-christi L.) leave.

\begin{tabular}{ll}
\hline Materials & Phenolic contents (ppm) \\
\hline Sidr leaves & $722.00 \pm 12.15$ \\
\hline Mean value \pm standard deviation (SD).
\end{tabular}

\subsection{Phenolic Compounds}

Identification of phenolic compounds by HPLC technique was used to identify the major phenolic compounds in the sidr juice (leaves) Fig 1. The identification was based on comparisons on the chromatographic retention time and UV absorbance spectra of compounds in sidr samples with those of authentic standards. Data of the HPLC analysis of sidr juice samples (leaves) are given in Fig. 2. Data show that the phenolic compounds of sidr juice (leaves) were made up of 13 compounds. The main phenolic compounds of leaves are (tyrosol, hydroxytyrosol, $P$-hydroxybezoic acid and vanillic acid).

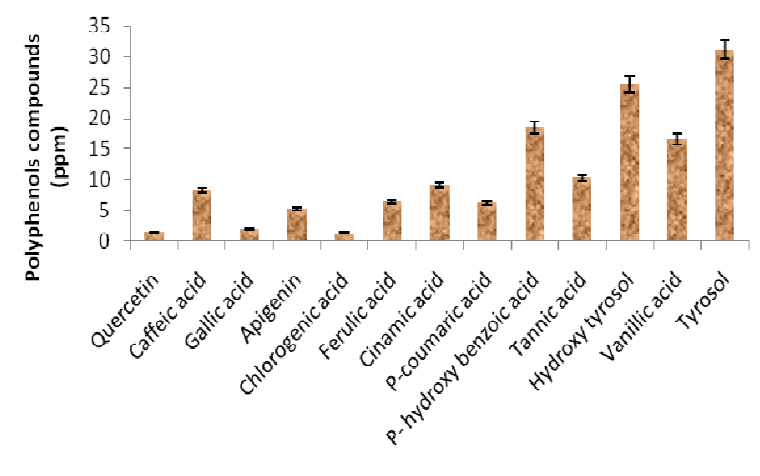

Compounds

Figure 1. Phenolic compounds (ppm) of sidr (Zizyphus spina-christi L.) leave. Mean value \pm standard deviation (SD).

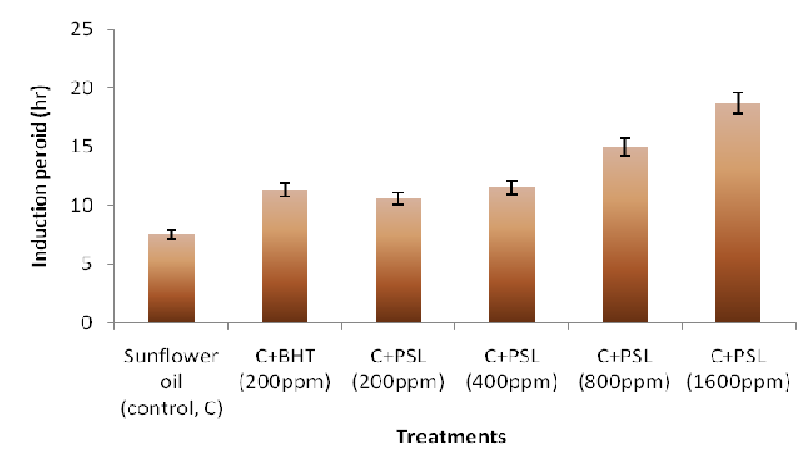

Figure 2. Effect of polyphenols obtained from sidr (leaves) on sunflower oil oxidative stability. Mean value \pm standard deviation (SD).

\subsection{The Antioxidant Activity of Sidr Phenolic Compounds}

The antioxidant activities of phenolic compounds from the sidr juice (leaves) were assessed by the Rancimat method. In this method the induction period for the onset of oxidative rancidity in sunflower oil was at $100^{\circ} \mathrm{C}$. In the present study, simple model systems comprising sunflower oil with phenolic compounds were used to assess oxidation behavior. An experiment was performed with sunflower and BHT (200ppm) to compare the antioxidant efficiency of the phenolic compounds from sidr with the most commonly used synthetic antioxidant material. It has been reported that synthetic antioxidants (BHT, BHA and PG) are added at concentrations of 100-400ppm to fats and oils to suppress the development of peroxides during food storage [43]. Therefore, the phenolic compounds were added to sunflower oil at concentrations of 200, 400, 800 and 1600ppm. Fig.3 shows the leaves of sidr on the oxidative rancidity of sunflower oil. The results illustrate that all the polyphenols of sidr juice and added at various concentrations to the test system, exhibited antioxidant activity.

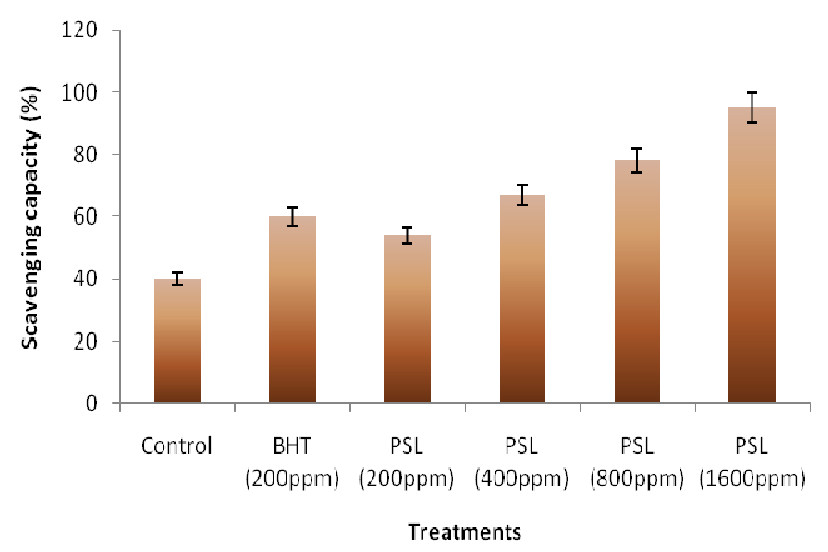

Figure 3. Scavenging capacity of DPPH free radicals by polyphenols sidr (leaves) and BHT. Mean value \pm standard deviation (SD).

\subsection{Scavenging Capacity of DPPH Free Radicals}

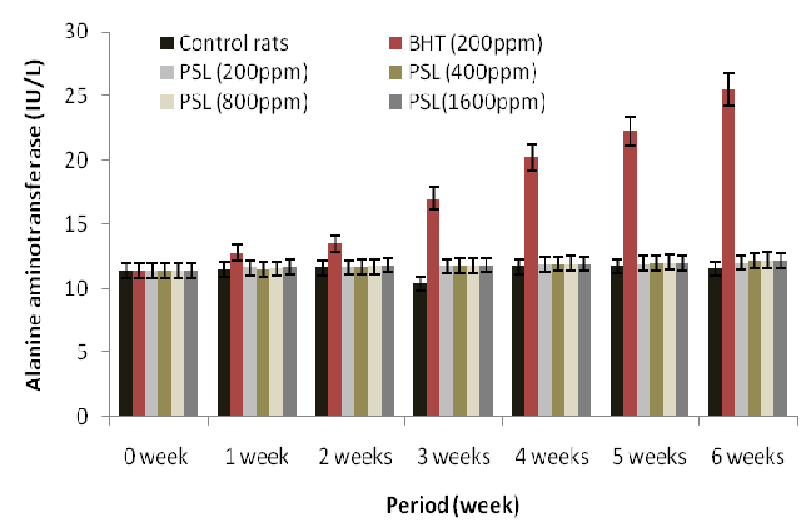

Figure 4. Influence of sidr (leaves) juice and BHT on the activity of serum alanine aminotransferase of rats $\left(I U / L^{-1}\right)$. Mean value \pm standard deviation $(S D)$. 
The changes in scavenging capacity of the phenolic compounds antioxidant measured with the hydrophobic DPPH free radical is shown in Fig. 4. Four levels of the concentrations of sidr juice phenolic compounds (leaves) were used with a very high scavenging capacity of 40.00 after only $10 \mathrm{~min}$. In all cases the scavenging capacity did not increase after the first $10 \mathrm{~min}$ of incubation. The reaction of BHT with DPPH was similar to phenolic compounds with DPPH; the scavenging capacities were similar.

\subsection{Alanine Aminotransferase (ALT), Aspartate Aminotransferase (AST) and Phosphatase Activities (AP)}

Figures 5, 6 and 7 show the activities of ALT, AST and AP for control rats and the values were slightly increased during the whole experiment ( 6 weeks). The administration of BHT at 200ppm to experimental rats induced significant increases in serum ALT and AST activities after 3 weeks from the commencement and towards the end of the experiment. In the mean time, BHT induced significant increase in serum AP activity after only 1 week from the beginning of the experiment. The administration of polyphenols in crude sidr juice (leaves) at 200, 400800 and $1600 \mathrm{ppm}$ did not cause any significant changes in enzyme activities compared with the control experiment. [44] mentioned that the rise in the activities of ALS, AST and AP in rat serum is a sign of hepatocellular damage. This case has been found in rats administered only BHT and not with polyphenolic of sidr juice (leaves).

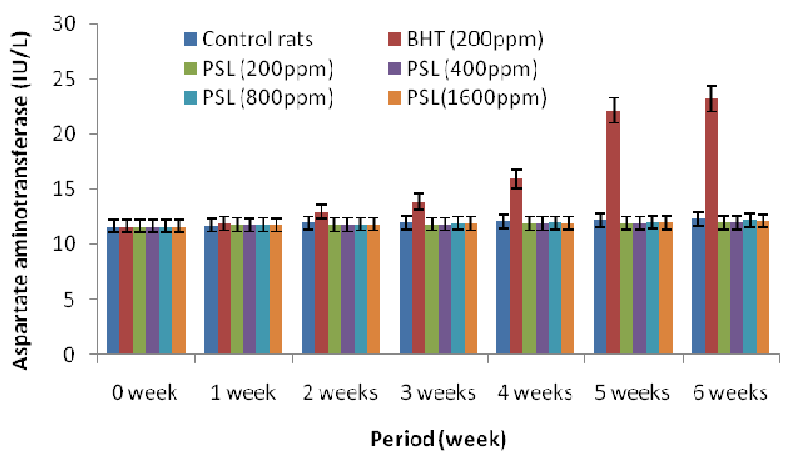

Figure 5. Influence of sidr (leaves) juice and BHT on the activity of serum aspartate aminotransferase of rats $\left(I U / L^{-1}\right)$. Mean value \pm standard deviation $(S D)$.

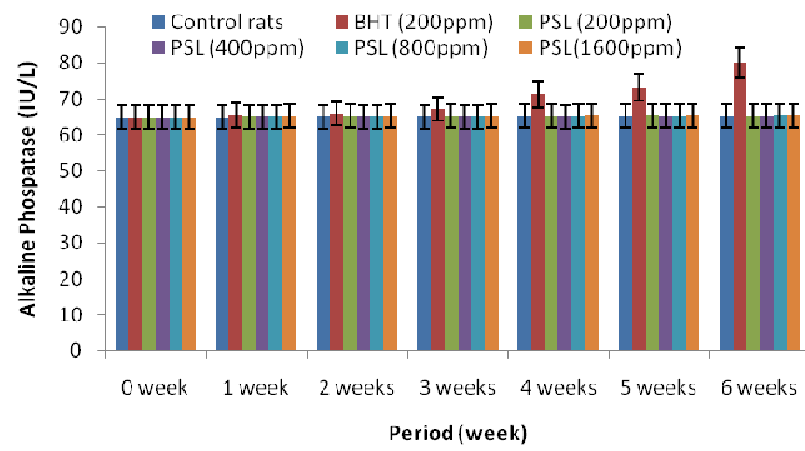

Table 6. Influence of sidr (leaves) juice and BHT on the activity of alkaline phosphatase of rats $\left(I U / L^{-1}\right)$. Mean value \pm standard deviation (SD).

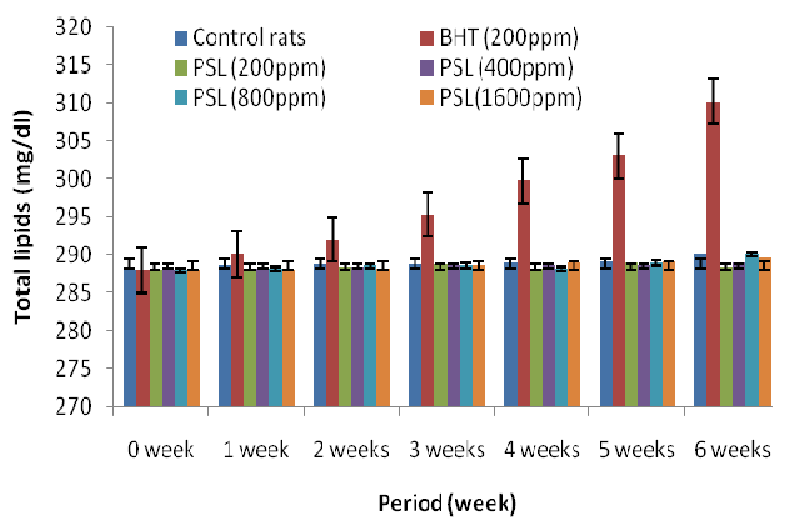

Figure 7. Influence of sidr (leave) juice BHT on the levels of serum total lipids of rats $\left(\mathrm{mg} / \mathrm{dl}^{-1}\right)$. Mean value \pm standard deviation $(S D)$.

\subsection{Serum Total Lipids}

The results (Fig. 8) show that there was no significant increase in the total lipids for control rats throughout the whole experiment. The administration of BHT at 200ppm caused significant and gradual increase in serum total lipids. The rise in total lipids at the end of the experiment was approximately 1.1 greater than that at the beginning of the experiment. The administration of polyphenolic compounds at 200, 400, 800 and 1600 ppm present in crude sidr juice (leaves) induced non-significant rise in rat serum total lipids. In other words, the several of phenolic compounds possessed the same function as that noticed with control rats.

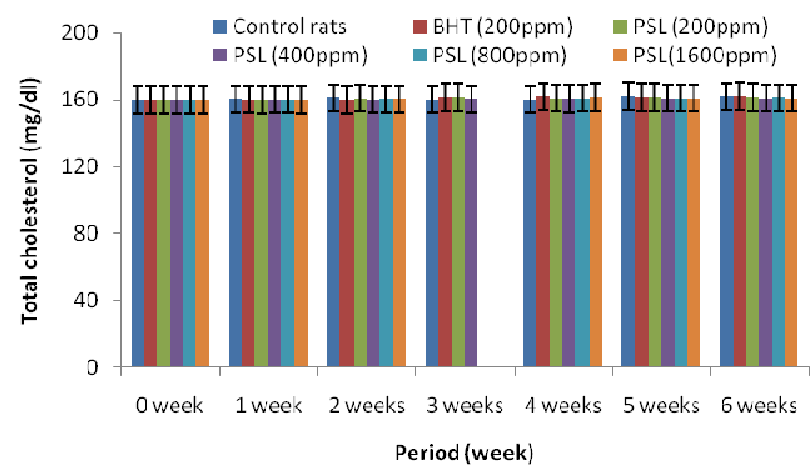

Figure 8. Influence of sidr (leaves) juice and BHT on the levels of serum total cholesterol of rats $\left(\mathrm{mg} / \mathrm{dl}^{-1}\right)$. Mean value \pm standard deviation (SD).

\subsection{Serum Total Cholesterol and Low-Density Lipoproteins Cholesterol}

Figures $(9 \& 10)$ show the levels of serum total cholesterol and low-density lipoprotein cholesterol (LDL-C) of control rats. Rats administered BHT (200ppm) and phenolic compounds (200, 400, 800 and 1600ppm) of crude sidr juice (leaves). The results for the control rats and rats administered BHT (200ppm), indicated that there were no significant increase in total cholesterol and LDL-C levels during the entire experiment. Also, administration of polyphenols of sidr (leaves) juice at various concentrations exhibited non-significant increases in the total cholesterol and LDL-C. 


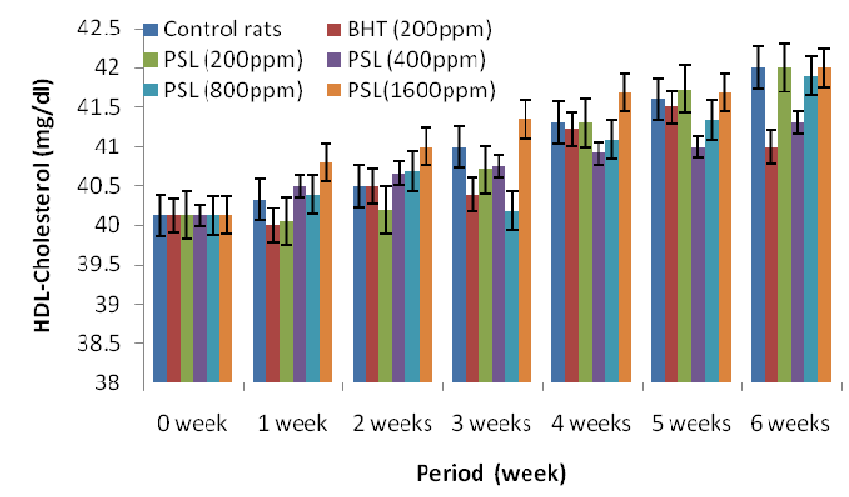

Figure 9. Influence of sidr (leaves) juice and BHT on the levels of serum $H D L$-cholesterol of rats $\left(\mathrm{mg} / \mathrm{dl}^{-1}\right)$. Mean value \pm standard deviation (SD).

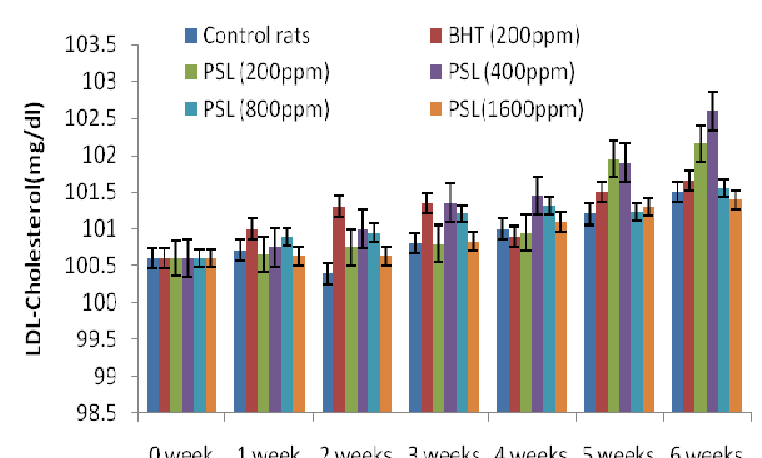

Period (week)

Figure 10. Influence of sidr (leaves) juice and BHT on the levels of serum $L D L$-cholesterol of rats $\left(\mathrm{mg} / \mathrm{dl}^{-1}\right)$. Mean value \pm standard deviation (SD).

\subsection{Serum High-Density Lipoprotein Cholesterol}

The results (Fig. 11) for the rats of the control and BHT group indicated that there was no significant rise in the levels of high-density lipoprotein cholesterol (HDL-C) throughout the whole experiment. Also, crude sidr juice (leaves) polyphenols at various concentrations induced non-significant rise in rat serum HDL-C.

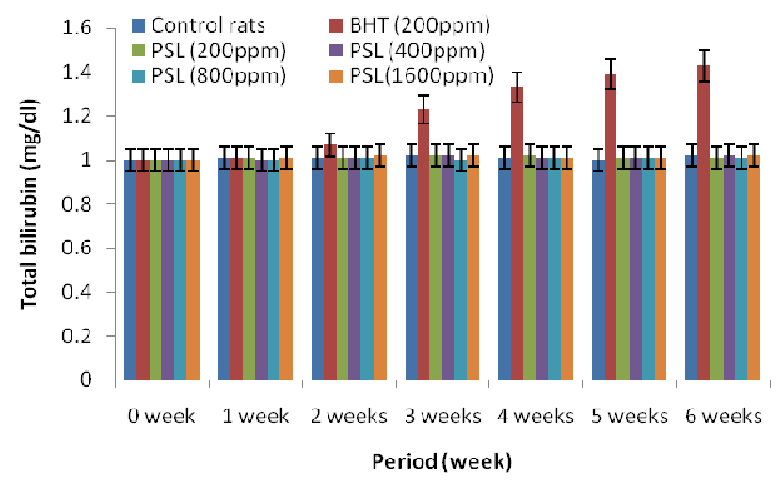

Figure 11. Influence of sidr (leaves) juice and BHT on the levels of serum total bilirubin of rats $\left(\mathrm{mg} / \mathrm{dl} \mathrm{l}^{-1}\right.$ ). Mean value \pm standard deviation (SD).

\subsection{Serum Total Bilirubin}

Fig. 11 shows the effect of sidr juice polyphenolic compounds (leaves) at various levels (200, 400, 800 and $1600 \mathrm{ppm})$ and BHT (200ppm) on the levels of rat serum total those administered various concentrations of phenolic compounds in sidr juice (leaves), did not show any changes in the levels of total bilirubin. Conversely, BHT 200ppm caused significant and gradual increases in total bilirubin levels during the entire experiment.

\subsection{Serum Uric Acid}

The data (Fig. 12) for the control rats and rats administered various concentrations of crude sidr juice (leaves) phenolic compounds showed non-significant changes in the levels of uric acid during the entire experimental period. On the contrary, BHT at 200ppm exhibited gradual increases on the levels of rat serum uric acid. It is worth noting that a significant increase in uric acid levels occurred at the second week and towards the end of experiment.

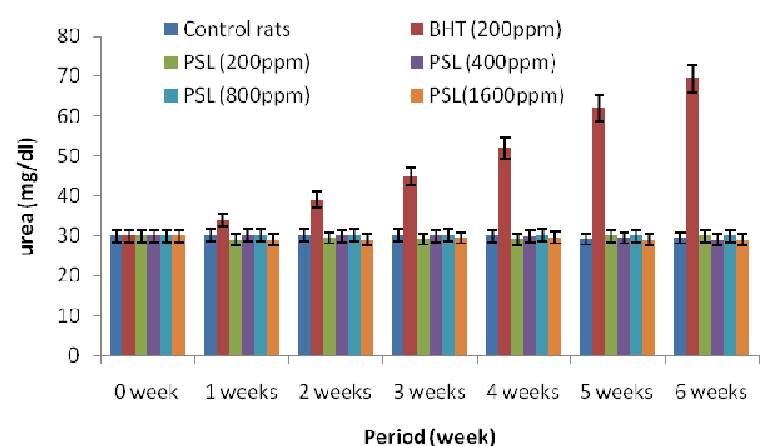

Figure 12. Influence of sidr (leaves) juice and BHT on the levels of serum urea of rats $\left(\mathrm{mg} / \mathrm{dl} \mathrm{r}^{-1}\right)$. Mean value \pm standard deviation $(S D)$.

\subsection{Serum Creatinine}

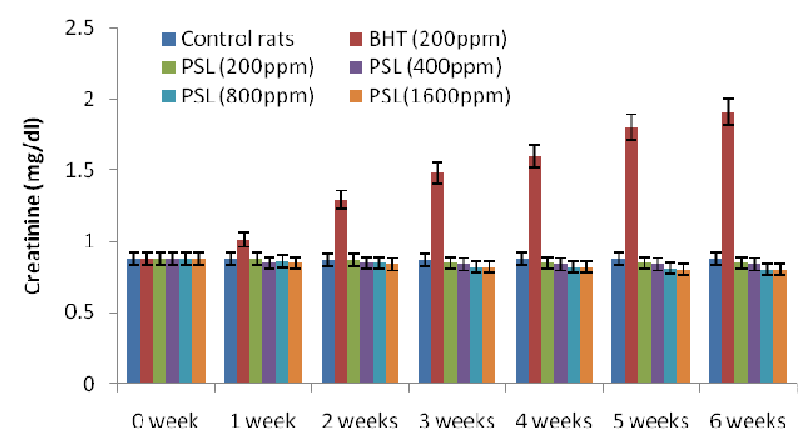

Period (weeks)

Figure 13. Influence of sidr (leaves) juice and BHT on the levels of serum Creatinene of rats $\left(\mathrm{mg} / \mathrm{dl}^{-1}\right)$. Mean value \pm standard deviation (SD).

The data (Fig. 13) for control rat group and the polyphenols rat groups indicate that there were no significant changes of serum creatinine levels during the entire experiment. In contrast, BHT at 200ppm caused increases in the levels of rat serum creatinine and the increase took place from the second week of the experiment. In generals, liver and kidney functions of rats administered crude sidr juice (leaves) did not cause any adverse effects in liver and kidney functions. Consequently, one would suggest adding crude sidr juice to increase their shelf-life of oils without any deleterious effect on human 
health. In general, the data for biochemical measurements demonstrate that the polyphenolic compounds of crude sidr juice are quite safe for human health. Conversely, the results made it clear that $\mathrm{BHT}$ as a synthetic antioxidant has to be abandoned from use.

\section{References}

[1] Pong K, (2003). Oxidative stress in neurodegenerative diseases: Therapeutic implications for superoxide dismutase mimetics. Expert Opinion in Biological Therapy, 3: 127-139.

[2] Bandyopodhyay M, Chakraborty R and Raychaudlhuri U (2007). A process for preparing a natural antioxidant enriched diary product. LWT-Food Science \& Technology, 40: 842-851.

[3] Seyuum A, Asres K and El-Fiky F K (2006). Structureradical scavenging activity relationships of flavonoids. Phytochemistry, 67: 2058-2070.

[4] Ammar R B, Bhour W, Sghaier M B et al. (2009). Antioxidant and free radical-scavenging properties of three flavonoids isolated from the leaves of Rhamnus alaternus L.: A structure-activity relationship study. Food Chemistry, 116: 258-264.

[5] Kahkonen M P, Hopia A I, Vuorela H J, et al. (1999). Antioxidant activity of plant extracts containing phenolic compounds. Journal of Agricultural \& Food Chemistry, 47: 3954-3962.

[6] Willams R J, Spencer J P and Rice-Evans C (2004). Flavonoids: Antioxidants or signaling molecular, Free Radical Biology \& Medicine, 36: 838-849.

[7] Ross J A and Kasum C M (2002). Dietary flavonoids: bioavailability, metabolic effects, and safety. Annu. Rev. Nutr. 22: 19-34.

[8] Bors W, Michel C and Stettmaier K (2001). Structureactivity relationships governing antioxidant capacities of plant polyphenols. Methods in Enzymology, 335: 166-180.

[9] Cai Y Z, Sun M and Xing J, et al. (2006). Structure-radical scavenging activity relationships of phenolic compounds from traditional Chinese medicine plants. Life Science, 78: 2872-2888.

[10] Branen A, (1975). Toxicology and biochemistry of butylated hydroxanisole and butylated hydroxytoluene. Journal of the American Oil Chemical Society, 52: 59-63.

[11] Youssef H E, Khedr A A. Mahran M Z (2011). Hepatoprotective activity and antioxidant effects of Napk (Zizyphus spina-christi L.) fruits on rats hepatoxicity induced by carbon tetrachloride. Nutrition Science, 9: 1-7.

[12] Zargari A (1988). Medicinal plants. Tehran University Press, Ira.2: $42-45$.

[13] Adzu B and Haruna A K (2007). Studied on the use of Zizyphus spina-christi $L$. against pain in rats and mice. African Journal of Biotechnology, 6: 1317-1324.

[14] Abalaka M E, Daniyan S Y and Mann A (2010). Evaluation of the antimicrobial activities of two Ziziphus species (Ziziphus mauritiana L. and Ziziphus spina-christi L.) on some microbial pathogens. Afr. J. Pharm. Pharmacol. 4(4):135-139.

[15] Han B H and Park M H (1986). Folk medicine: The art and science. The American Chemical Society, Washington DC, P.205.

[16] Kirtikar K R and Basu B D (1984). Indian medicinal plants, Lalit Mohan Basu, Allahabad, P.593.

[17] Adzu B, Amos S, Wambebe C et al. (2001) Antinociceptive activity of Zizyphus spina-christi root bark extract. Fitoterapia, 72: 334-350.

[18] Kaaria I (1988). Seed production, dispersal and germination in cryptostegia grandifolia and zizphus mauritiana, two invasive shrubs in tropical woodlands of Northern Australia. Australia Journal Ecology, 21: 324-331

[19] Michel A (2002). Tree, shrub and liana of West African zone. Margraf Publishers GMBH, Paris, P. 440.

[20] Abdel-Wahhab M A, Omar E A, Abdel-Galil, M M et al. (2007). Zizyphus spina-christi L. extract protect against aflatoxin BI initiated hepatic carcinogenicity. African Journal Traditional, Complementary \& Alternative Medicines, 4: 248-256

[21] Adzu B, Amos S, Amiza M B et al. (2003). Evaluation of the antidiarrhoeal effects of Zizyphus spina-christi L. stem bark in rats. Acta Tropica, 87: 245-250.

[22] Asgarpanah J and Haghighat E (2012). Phytochemistry and pharmacologic properties of Zizyphus spina-christi L. willd. African Journal of Pharmacy \& Pharmacology, 6: 23322339.

[23] Nazif M N (2002). Phytoconstituents of Zizyphus spinachristi $L$. fruits and their antimicrobial activity, Food Chemistry, 76: 77-81.

[24] El-kamali, H H and Mahioub S A (2009). Antibacterial activities of francoeuria crispa, pulicaria undulate, Zizyphus spina-christi and cucurbita pepo against seven standard pathogenic bacteria. Ethnobotany, Leaflets, 13: 722-733.

[25] Alsaimary I E (2012). A study of antibacterial activity of plant extracts on bacterial pathogens isolated from eye infections. International Journal Microbiology. 4: 1-5.

[26] Korji S H A (2012). Inhibition of nitrate reductase production from Gram-negative bacteria using Ziziphus spina-christi extract and comparing with some antibiotics. Iraqi J. Agric. Sci. 43(2):144-150.

[27] Rhee M H, Park H J, Cho J Y (2009). Salicornia herbaceae: Botanical, Chemical and pharmacological review of halophyte marsh plant. J. Med. Plants Res. 3(8):548-555.

[28] Gutfinger T (1981). Polyphenols in olive virgin oils, Journal American Oil Chemical Society, 58: 996-998.

[29] Mateos R, Espartero J L, Trujillo M et al. (2001). Determination of phenols, flavones and lignanes of virgin olive oils by solid phase extraction and high performance liquid chromatography with diode array ultraviolet detection. Journal Agricultural Food Chemistry, 49: 2185-2192.

[30] Gutierrez, F. (1989): Determination de la estabilidade oxidative de acuities de olive virgrnes. Comparacion entre del metodo A. O. M. Y. el metodo Rancimat. Grasas Y Aceities, 40: 1-5. 
[31] Cheel C J, Theoduloz C, Rodriguez J A et al. (2007). Freeradical scavenging activity and phenolic content in achenes and thalamus from Frgaria chilonsis ssp. Food Chemistry, 102: $36-44$

[32] A O A C (2005). Official Methods of Analysis of the Association of Official Analytical Chemists, $18^{\text {th }}$ edn (edited by W. Horwitz). Pp. 62. Gaithersburg, MO: AOAC.

[33] Schermer S. (1967). The blood morphology of laboratory animals. Pp. 350. Philadelphia: FA, Davis Co.

[34] Kachmar J F. and Moss, D W. (1976). Enzymes. In: Fundamentals of Clinical Chemistry (edited by N. Tiez). Pp. 666-672. Philadelphia, PA: W. B. Saunders Co.

[35] Bergmryer H U and Harder M (1986). A colorimetric method for determination of serum glutamic oxaloacetic and glutamic pyruvic transaminase. Clinical Biochemistry, 24: 28-34.

[36] Varley H, Gewnlock A and Bell M (1980). Practical clinical biochemistry, Vol. 1, $5^{\text {th }}$ edn. Pp. 741, 897. London: Williams Heinemen Medical Books, Ltd.

[37] Fawcett J K, and Scott J E (1960). Enzymatic, colorimetric method for determination urea in serum, plasma and urine. Journal of clinical Pathology, 13: 156-162.
[38] Dounas B T, Perry B and Jenderze-Jczak L (1981). Colorimetric method for determination total bilirubin, direct and indirect bilirubin. Clinical Chemistry, 33: 1349-1356.

[39] Barham D and Trinder P. (1972). Enzymatic colorimetric method for determination uric acid in serum plasma and urine. Analyst, 97: 142-146.

[40] Roechlau P, Bernt E and Gruber W L (1974). Kinetics of the cholesterol sulfuric acid reaction. A fast kinetic method for serum cholesterol. Clinical Chemistry \& Clinical Biochemistry, 12: 403-408.

[41] Assmann G (1979). Cholesterol determination in high density lipoproteins separated by three different methods. Internist, 20: 559-604.

[42] Frings C S and Dunn R T (1979). Colorimetric method for determination total serum lipids based on the sulphopospho vanillin reaction. Am. J. Clin. Pathol. 53: 89-91.

[43] Allen J C and Hamilton R J (1983). Rancidity in foods. Pp. 85-173. London and NewYork: Applied Sinece Publishers.

[44] Baron D N (1987). A short textbook of chemical pathology, $4^{\text {th }}$ edn. Pp. 188-228. Kent, Great Britain: English Langgoage book Society Hadder \& Stoghton Ltd. 